\title{
GPR Aplicado na Investigação de Fatores que Levaram ao Colapso parte de um Pavimento Asfáltico
}

Vicente Luiz Galli (IPT), Wilson Shoji lyomasa (IPT) e Leonildes Guireli Netto (IPT)

Copyright 2019, SBGf - Sociedade Brasileira de Geofísica

This paper was prepared for presentation during the $16^{\text {th }}$ International Congress of the Brazilian Geophysical Society held in Rio de Janeiro, Brazil, 19-22 August 2019.

Contents of this paper were reviewed by the Technical Committee of the $16^{\text {th }}$ International Congress of the Brazilian Geophysical Society and do not necessarily represent any position of the SBGf, its officers or members. Electronic reproduction or storage of any part of this paper for commercial purposes without the written consent of the Brazilian Geophysical Society is prohibited.

\section{Abstract}

This paper presents the results of a research developed with Ground Penetrating Radar (GPR) referring to the investigation of possible factors that caused the collapse of the central part of the pavement of an avenue due to the emergence of a hole. The geophysical survey with Ground Penetrating Radar (GPR) aimed to identify the interfaces between the different constituent layers of the pavement, determine their thicknesses, verify the technological conditions of the materials constituents of these layers, investigate the presence of voids and groundwater pipelines. The use of Ground Penetrating Radar (GPR) proved to be quite effective, allowing to identify the thicknesses of the layers that structure the pavement, the pipes present in the area and a region of alteration that was associated with the possible cause of the collapse of the avenue pavement.

\section{Introdução}

Apresentam-se os resultados de uma pesquisa tecnológica desenvolvida com uso de radar (GPR) na investigação de possíveis fatores técnicos que podem ter provocado o colapso da parte central do leito de um pavimento asfáltico, e como consequência abriu um buraco na superfície de uma avenida da Cidade Universitária de São Paulo, como mostra a Figura 1.

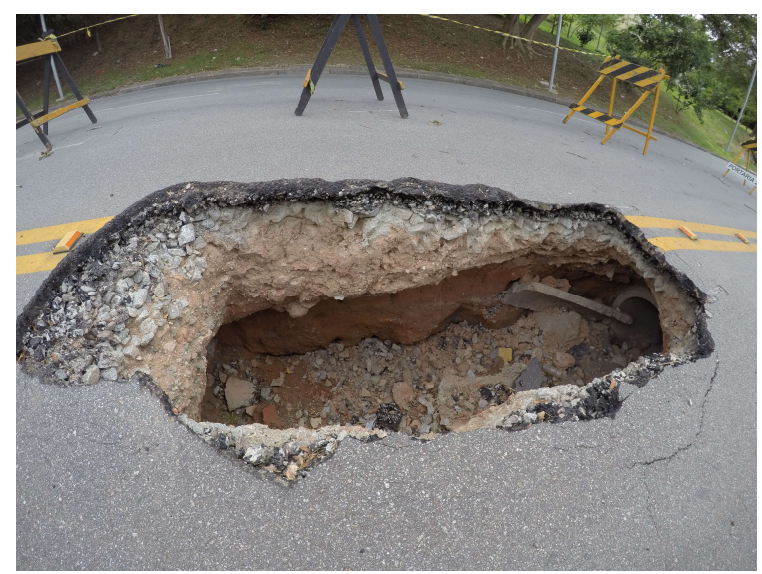

Figura 1 - Vista do buraco aberto no centro da avenida.

\begin{abstract}
Segundo os técnicos da Prefeitura da Cidade Universitária, o colapso no mesmo local é recorrente, e os registros mostram que, neste mesmo ponto, ocorreram dois eventos anteriores nos últimos três meses. Os reparos realizados logo após aos dois primeiros eventos, como reaterro e pavimentação, foram executados sem que as causas do seu surgimento tenham sido investigadas.
\end{abstract}

Assim, com intuito de compreender o processo instalado no local, bem como, investigar os fatores técnicos que levaram o surgimento desse buraco por três vezes ocasionando interrupção do trânsito e transtornos aos usuários que circulam pela avenida, procedeu-se a um levantamento geofísico com radar (GPR).

Esse levantamento com GPR teve por objetivo reconhecer as interfaces entre as diferentes camadas constituintes do pavimento (base, sub-base e subleito), bem como, determinar suas respectivas espessuras, verificar as condições tecnológicas dos materiais constituintes dessas camadas (por exemplo, desagregação) e investigar na área adjacente a presença de vazios e até canalizações subterrâneas utilizadas para diferentes propósitos, como para o escoamento de águas pluviais, redes de água para abastecimento, rede de gás que pudessem estar associadas aos fatores que provocaram o colapso da parte central do leito da avenida de forma a orientar as intervenções de reparos no pavimento asfáltico.

A escolha na utilização do método não destrutivo com radar se deu por três razões principais: a) A primeira delas foi decorrente da excelente resposta obtida em trabalhos realizados anteriormente pelo IPT, sobretudo em trechos com pavimento asfáltico. Nesses trabalhos verificou-se o alto contraste dielétrico entre os materiais usados na pavimentação e nas camadas de base e subbase (asfalto/brita). A segunda razão foi pela rapidez na execução do ensaio, portanto de baixo custo. A terceira foi devido à possibilidade de se avaliar a situação do pavimento in situ, de forma contínua e não causar danos na camada asfáltica, e por conseguinte, orientar a locação de sondagem.

\section{Método}

O sistema de radar, usado neste trabalho, transmite pulsos de energia eletromagnética com frequência de $250 \mathrm{MHz}$ por meio uma antena dipolar. As ondas EM penetram no subsolo e são refletidas nas interfaces constituídas por materiais que possuem propriedades dielétricas diferentes, como a interface entre o solo e uma tubulação de concreto. As ondas refletidas são registradas pelo sistema como sinais de amplitude em 
função do tempo transcorrido entre a emissão da onda no transmissor e a chegada da onda no receptor. A profundidade de penetração é calculada com base na velocidade de propagação da onda através do material. $A$ antena é deslocada na superfície do terreno e um novo pulso é enviado, repetindo o processo e, assim, uma seção dos registros da posição-profundidade é gerada. A Figura 2 ilustra o esquema de obtenção dos dados do radar.

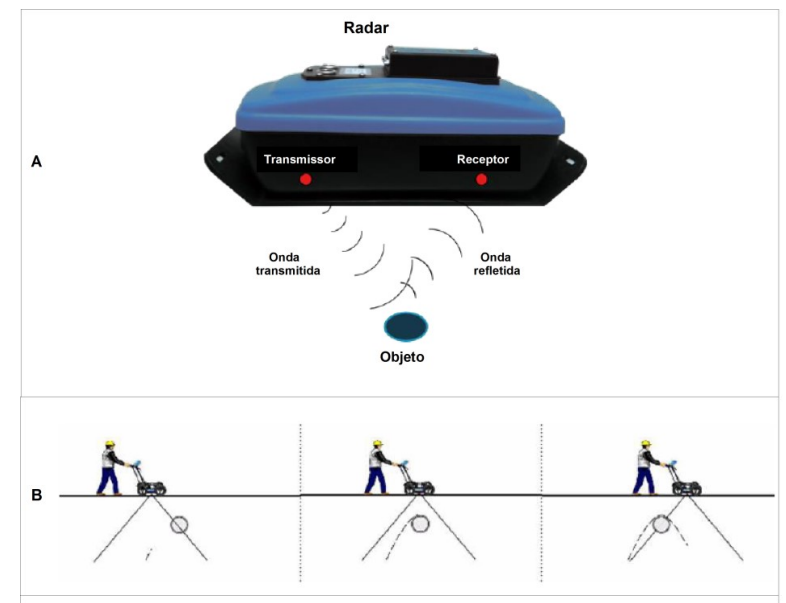

Figura 2 - a) Onda transmitida e onda refletida; b) Resposta a ser obtida com o radar devido a uma tubulação enterrada é uma hipérbole.

\section{Trabalhos Realizados}

Foram marcados sobre o pavimento da avenida, 4 perfis longitudinais e 26 perfis transversais com espaçamento médio entre si de 2 metros. A Figura 3 mostra um croqui com a localização dos perfis de radar realizados, a posição do buraco, um tampão metálico e uma boca de lobo, observados no pavimento após uma inspeção visual no local.

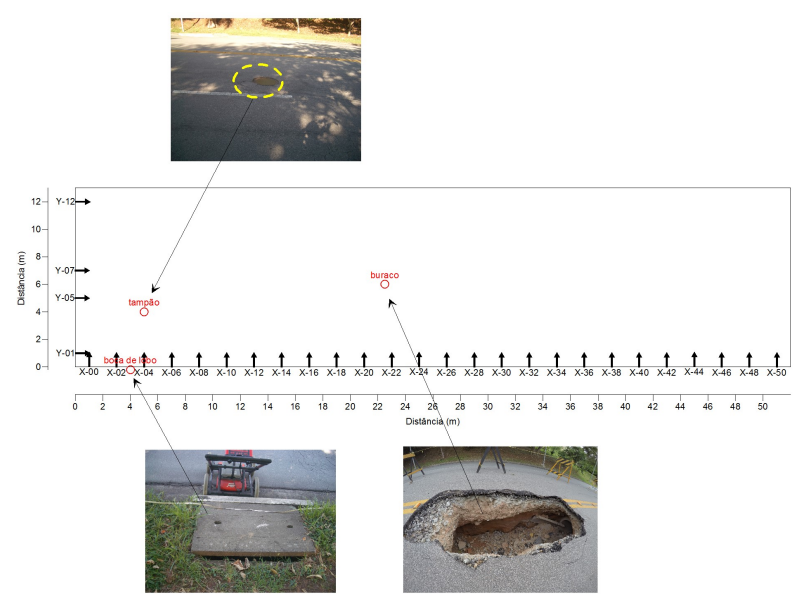

Figura 3 - Croqui com a localização dos 30 perfis, identificados por $X-00$ e $y$-01 realizados com o radar sobre o pavimento da avenida.

As medidas com o radar foram obtidas com um equipamento RD1000 Radiodetection com antena de 250
$\mathrm{MHz}$, configurado para investigar o subsolo até a profundidade de 3 metros. Os registros foram feitos ao longo dos 30 perfis.

\section{Resultados}

Os resultados do levantamento geofísico com radar são apresentados na forma de figuras referenciadas: distância ao longo do perfil e em função da profundidade investigada.

A interpretação teve como foco principal determinar as interfaces entre camadas constituídas de materiais de diferentes naturezas, como pedra britada e solo, detectar redes de tubulações enterradas utilizadas para diferentes propósitos, e investigar a presença de vazios.

A fim de se compreender melhor os fatores que levaram ao colapso do leito da avenida, deu-se um foco de detalhamento na região do entorno do buraco, para isso analisaram-se as seções das linhas $x-20, x-22, x-24, x-$ $26, y-1, y-5, y-7$ e $y-12$.

As Figuras 4 e 5 mostram em 3D as seções de radar dos perfis $x-20, x-22$ e $y-12$ realizados próximo ao colapso. Destacam-se nestas seções a presença de duas anomalias hiperbólicas nas posições $2 \mathrm{~m}$ e $6 \mathrm{~m}$ ao longo do perfil e em profundidades entre $1,2 \mathrm{~m}$ e 1,3 $\mathrm{m}$ e as fontes causadoras dessas anomalias foram atribuídas à presença de tubulações. Destaca-se também nas seções de radar uma forte anomalia de forma contínua a $50 \mathrm{~cm}$ de profundidade que foi associada à interface entre a camada de "bica corrida" e o solo compactado. A "bica corrida" é uma mistura de materiais composto por britas, pedrisco e pó de pedra usado comumente como base na pavimentação de estradas e avenidas. Chama a atenção nesta seção o conjunto de interfaces descontinua em lateralidade, porém com persistência em profundidade assinalada na seção por um círculo tracejado na cor azul.

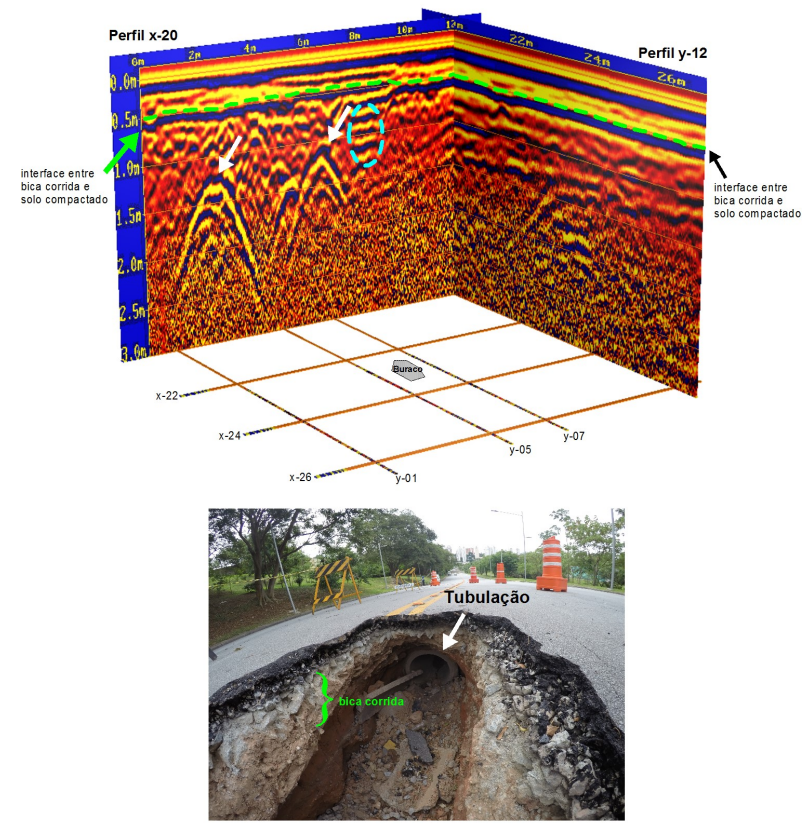

Figura 4 - Visualização $3 D$ das seções de radar dos perfis $x-20$ e $y-12$ realizados ao lado do colapso. A seta branca na posição $6 \mathrm{~m}$ da seção mostra a anomalia 
hiperbólica que foi associada ao tubo de concreto como sendo a fonte causadora da anomalia como pode ser visto na foto. A linha tracejada na cor verde indica a interface entre a camada de "bica corrida" e o solo compactado acima do tub,o como mostra a imagem do buraco. O círculo tracejado na cor azul (seção de radar) pode estar associado a alterações nas condições dos materiais (como por exemplo desagregação) utilizados como base ou sub base do pavimento.

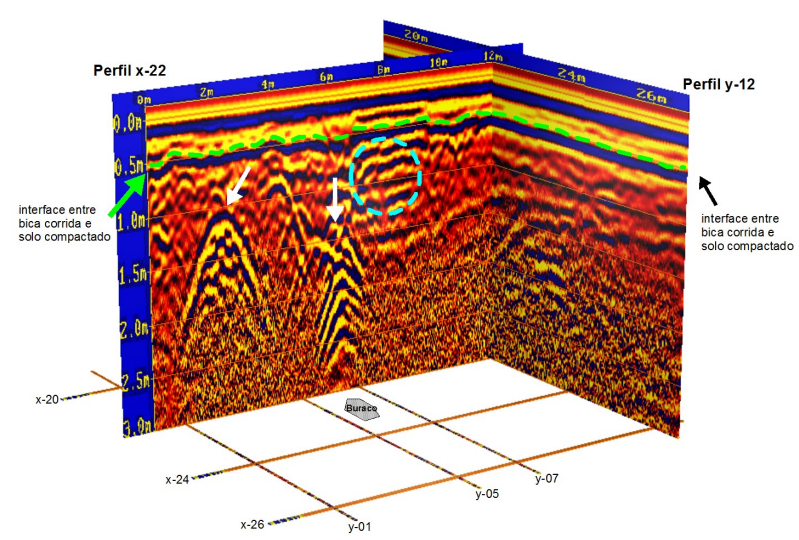

Figura 5 - Visualização $3 D$ das seções de radar dos perfis $x$-22 e $y$-12 realizados ao lado do colapso. Anomalias similares às da Figura 4 são observadas nesta seção: a) seta branca (anomalia hiperbólica) associada a tubo de concreto; b) linha tracejada verde indica interface entre a "bica corrida" e solo compactado; e c) círculo tracejado em azul que pode estar associado a desagregação de materiais.

As Figuras 6 e 7 trazem os quatro perfis transversais à avenida no sentido do caminhamento para os pontos acima mencionados. Assim, destacam-se aspectos técnicos relevantes a respeito dos dados obtidos no levantamento com o GPR. Na região central do perfil, com profundidade de 1,2 metros, ocorre uma anomalia hiperbólica bem marcada no perfil $x-20$, porém no perfil $x$ 22 essa anomalia se apresenta um pouco alterada no padrão do sinal, evidenciando um possível início de ruptura da tubulação. A hipótese ganha respaldo quando no perfil $x-24$ não se observa mais o registro do sinal hiperbólico nessa profundidade, sugerindo a ausência da tubulação nessa região. No perfil $x-26$, por sua vez, na profundidade de $1 \mathrm{~m}$ a anomalia hiperbólica volta a ser registrada, deixando claro que o rompimento da tubulação ocorreu entre os perfis x-22 e x-24.

Outra anomalia hiperbólica bem nítida observada nos perfis $x-20$ e $x-22$ ocorre à esquerda na profundidade de $1,2 \mathrm{~m}$ no primeiro perfil e $1 \mathrm{~m}$ no segundo. Entretanto, nos perfis $x-24$ e $x-26$ essa anomalia hiperbólica deixa de ocorrer, sendo substituida por multiplas reflexões e difrações do sinal, indicando uma zona de alteração nas condições tecnológicas dos materiais da sub base podento futuramente ocasinar desagregação do revestimento asfaltico e até um colapso.

Por fim, na região central do perfil, entre a interface da camada de "bica corrida" e solo compactado e a anomalia hiperbólica, entre as profundidades de $0,5 \mathrm{~m}$ e $1 \mathrm{~m}$, nota-se uma interface descontinua na lateralidade, porém com persistência em profundidade de aproximadamente $0,5 \mathrm{~m}$. Essa interface pode ser indicativa de um solo com deficiência na compactação (ou em processo de desagregação) que ao receber a sobrecarga provocada pelo tráfego contínuo de veículos na via, promove o abatimento da camada de solo e, por consequência, provoca o rompimento da tubulação. Para caracterizar essa deficiência, foi sugerida a execução de investigação por meio de sondagens a percussão.

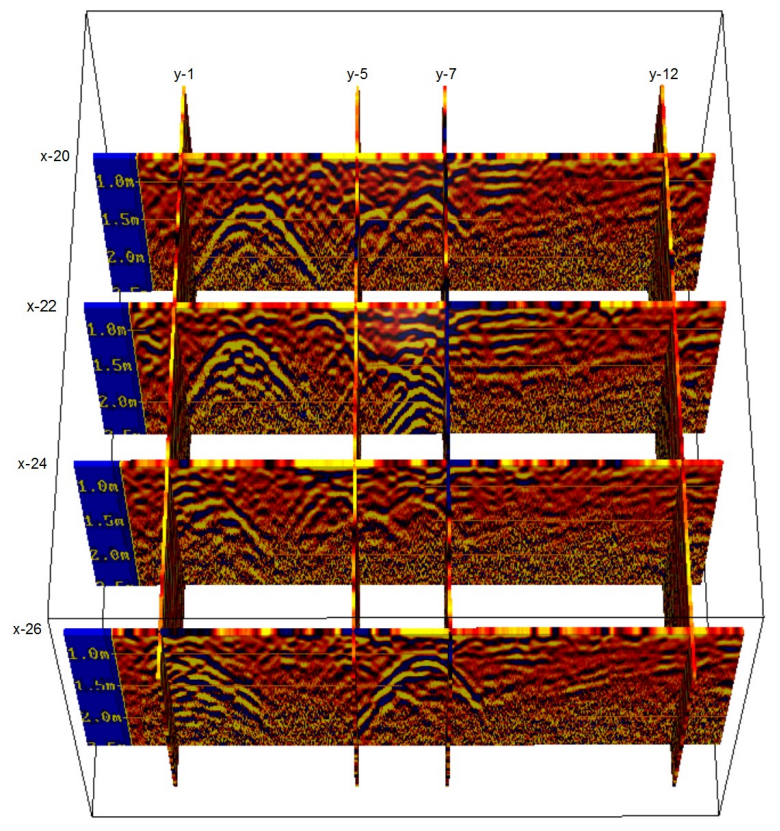

Figura 6 - Visualização $3 D$ de quatro seções de radar (perfis $x-20, \quad x-22, \quad x-24$ e $x-26$ ) realizadas sobre $o$ pavimento perpendicularmente a avenida no entorno do colapso. Nota-se a presença de anomalias hiperbólicas que foram atribuidas à presença de tubulações. 


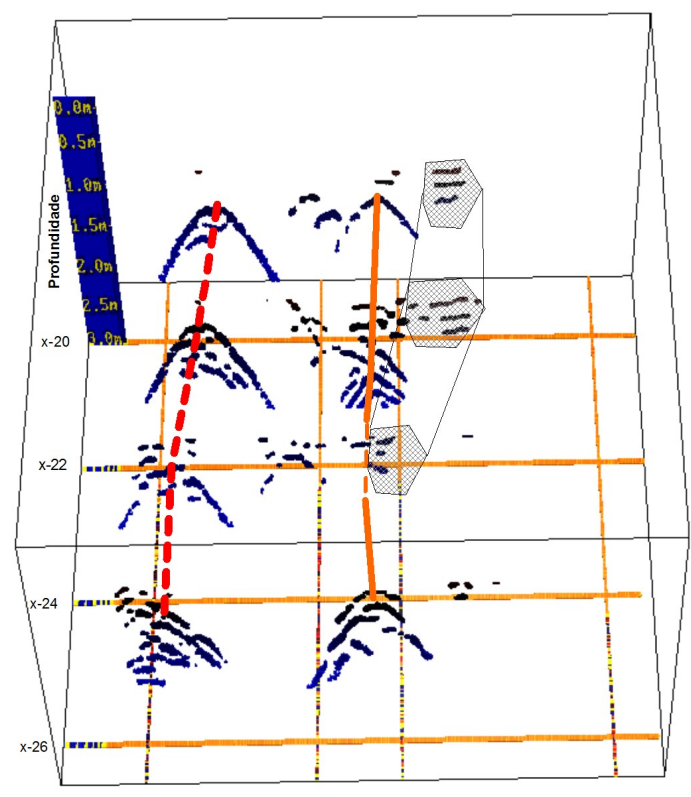

Figura 7 - Visualização $3 D$ das quatro seções de radar (perfis $x-20, x-22, x-24$ e $x$-26) interpretadas. A linha tracejada em vermelho conectando as hipérboles indica a tubulação 1, a linha contínua na cor laranja mostra a tubulação 2 que rompeu entre $x-22$ e $x-24$ e a região hachurada corresponde a zonas de alteração das condições tecnológicas dos materiais.

A Figura 8 apresenta esquematicamente em 3D as seções de radar dos perfis $x-00, x-50, y-01$ e $y-12$ ao redor de toda a área investigada com GPR.

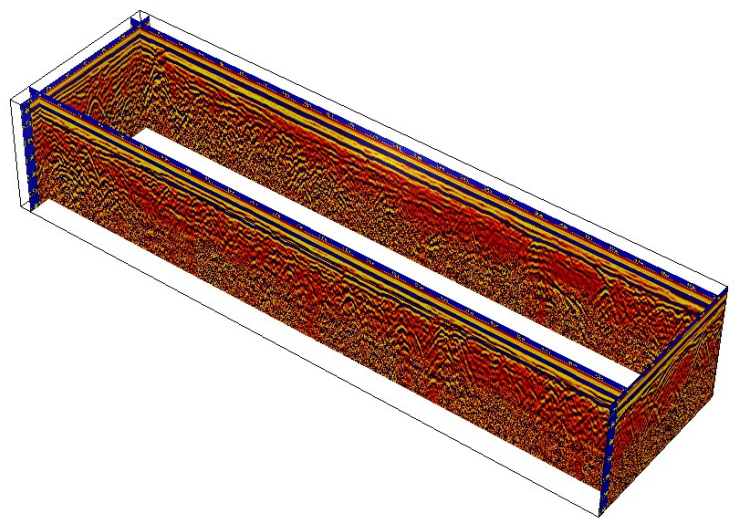

Figura 8 - Visualização $3 D$ esquemática das seções de radar dos perfis $x-00, x-50, y-01$ e $y-12$ do limite da área investigada com GPR.

A Figura 9 sintetiza em 3D as anomalias observadas em todos os perfis transversais realizados sobre o pavimento da avenida. É possível notar ao longo da avenida uma sequência de anomalias hiperbólicas, associadas à presença de tubulações, entretanto, existe um ponto, próximo aos primeiros metros do caminhamento, onde ocorre uma "lacuna" da hipérbole, associado ao rompimento da tubulação nesse trecho. Outro ponto que merece destaque é a região em que ocorre uma interface descontínua na lateralidade, porém com persistência em profundidade indicando uma possível presença de um material mal compactado ou em processo de desagregação. É importante notar que tal anomalia não se observa em todo o perfil e, por ocorrer justamente na área do colapso do leito da avenida, pode estar associada às causas do problema.

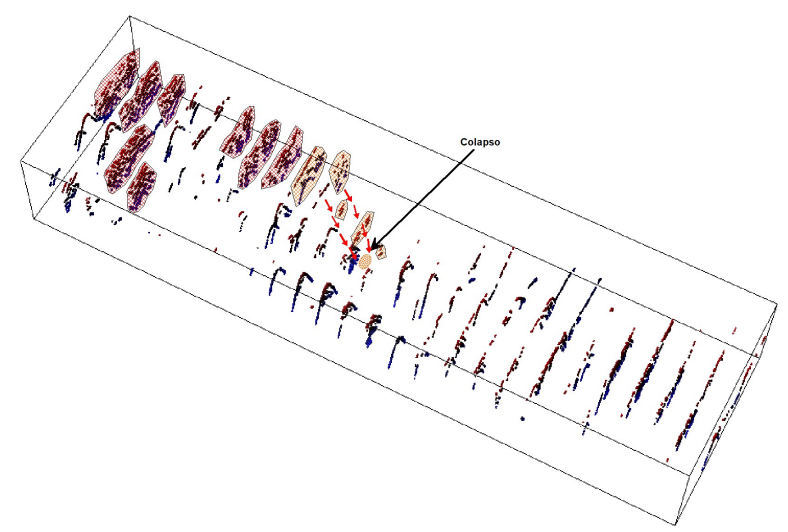

Figura 9 - Visualização $3 D$ das anomalias de GPR reveladas em toda área investigada. Foco na região próxima ao colapso do leito da avenida, a ausência das anomalias hiperbólicas seriam um indicativo do rompimento da tubulação na área. Outra anomalia importante está marcando uma sequencia de interfaces em profundidade, indicativo de alterações nas condições dos materiais que compoem a camada, acredita ser um evento de desagregação do material.

\section{Conclusões}

A utilização do método do radar (GPR) mostrou-se bastante eficaz, uma vez que foi possível identificar, as espessuras das camadas que estruturam o pavimento asfáltico, a indicação do posicionamento de tubulações subterrâneas na área e o intervalo de uma anomalia, associada ao colapso da parte central do leito da avenida.

A interpretação dos dados coletados mostrou também a existência de uma região com alterações nas indicações de anomalias continuas, associadas à interface entre a camada de asfalto/brita e o solo compactado, além do trecho da perda de sinal, indicando uma zona de fraqueza, sendo, portanto, o foco a ser investigado.

Por fim, o método GPR também identificou com precisão o posicionamento de tubulações subterrâneas, representadas pelas anomalias hiperbólicas nos perfis de radar; eventos de difração e múltiplas reflexões devido à presença de vazios (tubo), como observado no buraco do pavimento, além da anomalia (solo mal compactado ou em processo de desagregação) já mencionada que aponta ser a possível causa do colapso do leito da avenida cumprindo com os objetivos previamente estabelecidos. E como sugestão técnica, indicou-se a execução de sondagens a percussão nessa área para certificar (ou não) a deficiência na compactação (ou desagregação do solo). A campanha de sondagem não 
foi executada e o reparo executado está apresentando pequeno abatimento.

\section{Referências Bibliográficas}

ASTM D 6432. 2005. Standard Guide for Using the Surface Ground Penetrating Radar Method for Subsurface Investigation. 17p.

Galli, V. L, Azevedo, A. A., Sousa, L. G. (2013). Ensaio Geofísico de GPR Aplicado no Mapeamento de Fundações. 13th International Congress of the Brazilian Geophysical Society, Rio de Janeiro.

Galli, V. L, Guirardi, D. M., Bressan, D. L. (2014). GPR Aplicado na Localização de Armadura em Estrutura de Concreto. VI Simpósio Brasileiro de Geofísica, Porto Alegre.

Galli, V. L, Guirardi, D. M. (2014). Uso do Radar no Desenvolvimento de Técnicas de Prospecção de Armadura em Estruturas de Concreto. VI Simpósio Brasileiro de Geofísica, Porto Alegre.

Galli, V. L, Guirardi, D. M., Bressan, D. L. (2015). GPR Imageamento 3D Aplicado na Investigação de Armaduras em Concreto. 14th International Congress of the Brazilian Geophysical Society, Rio de Janeiro.

Galli, V. L.; Guirardi, D. M. (2015) GPR Aplicado na Investigação da Estrutura de um Pontilhão. 14th International Congress of the Brazilian Geophysical Society, Rio de Janeiro. Rio de Janeiro. 4p.

Galli, V. L.; Vieira, R., Alencar, C.L. (2017) GPR Aplicado na Investigação de Pavimentos. 15th International Congress of the Brazilian Geophysical Society \& EXPOGEF, Rio de Janeiro, Brasil.

Infrasense, Inc. (2006) Feasibility of Using Ground Penetrating Radar (GPR) for Pavements, Utilities, and Bridges. South Dakota Department of Transportation Office of Research. SD2005-05-F

Maser, K., Carmichael, A. (2015) Ground Penetrating Radar Evaluation of New Pavement Density. Paving Project - SR 539 in Lynden, WA.

Sandmeier, K.J. (2016) Reflexw - Program for processing of electromagnetic reflection, refraction and transmission data - version 8.2 Germany.

Sauck, W. A. 1997. Radar applied to environmental problems and groundwater prospection. 5th International Congress of the Brazilian Geophysical Society, São Paulo. Short course.

Tillard, S., Dubois, J.C. (1995) Analysis of GPR Data: Wave Propagation Velocity Determination. Journal of Applied Geophysics, 33, p. 77-91. 